\title{
Article \\ Long-Term Reliability Characteristics of OLED Panel and Luminaires for General Lighting Applications
}

\author{
Jeungmo Kang ${ }^{1, * \mathbb{D}}$, Yoonhee Cho $^{2}$ and Woojin Jang ${ }^{3}$ \\ 1 Lighting Center, Korea Testing Certification Institute, GyeongGi-Do 15809, Korea \\ 2 HCL Research Team, Korea Institute of Lighting \& ICT, GyeongGi-Do 14523, Korea; 0808jyh@kilt.re.kr \\ 3 Department of Electrical and Information Engineering, Seoul National University of Science \& Technology, \\ Seoul 01811, Korea; hight@seoultech.ac.kr \\ * Correspondence: jmkang@ktc.re.kr; Tel.: +82-31-428-7321
}

check for

updates

Citation: Kang, J.; Cho, Y.; Jang, W. Long-Term Reliability Characteristics of OLED Panel and Luminaires for General Lighting Applications. Appl. Sci. 2021, 11, 74. https:// dx.doi.org/10.3390/app11010074

Received: 23 October 2020

Accepted: 22 December 2020

Published: 23 December 2020

Publisher's Note: MDPI stays neutral with regard to jurisdictional claims in published maps and institutional affiliations.

Copyright: (c) 2020 by the authors. Licensee MDPI, Basel, Switzerland. This article is an open access article distributed under the terms and conditions of the Creative Commons Attribution (CC BY) license (https: / / creativecommons.org/ licenses/by/4.0/).
Featured Application: Organic light-emitting diode (OLED) is one of the candidates for future lighting sources since it may solve problems of LED light source. There are some studies on long-term reliability characteristics of OLED light source. However, these studies focused on the light output degradation of OLED light sources mainly. This paper focuses on the investigation of the long-term characteristics of OLED panels and luminaires in terms of maintained optical and electrical characteristics including color quality, also. The analyzed results show that commercial OLED products have enough performances for the general lighting application from the consumer's point of view.

Abstract: Organic light-emitting diode is one of the future-proof solid-state-based lighting sources. OLED shows great aesthetic advantages and good color quality without glare. Moreover OLED is a kind of surface light sources naturally. There are some studies on the long-term reliability characteristics of OLED light source. However, these studies focused on the light output degradation of OLED light sources mainly. In this paper, we have investigated the long-term reliability characteristics of OLED panel and luminaires in terms of lumen maintenance, correlated color temperature, color rendering index, and operating voltage. Total twelve OLED panels with four different kinds and six OLED luminaires with two different kinds were analyzed up to six thousand hours and analyzed for the general lighting applications.

Keywords: organic light-emitting diode; lumen maintenance; reliability; general lighting; OLED lighting

\section{Introduction}

After the invention of blue light emitting diode (LED), most of the conventional lighting sources for general lighting applications are replaced by LED-based light sources. LED-based light sources have advantages to the conventional ones in terms of guaranteed longer life, lower power consumption, higher brightness, and less harmfulness for the environment [1-4]. However, there are some disadvantages of LED-based light source. For example, heat generated from the junction in light emitting diode chip must be managed properly to prevent over-heating, which may damage the chip and/or cause degradation of materials in the package. As more light is produced from the high-power LED, industries keep developing more efficient heat-dissipating materials. Some are concerned about the use of high-power LED light sources which may raise potential risk to human health because of the blue spectrum from the LED [5]. LED itself is a kind of point light source; the glare of LED light source is another problem.

Organic light-emitting diode (OLED) is one of the future-proof solid-state-based lighting sources since it may solve problems mentioned above. It has lower blue spectrum and surface light sources naturally. Moreover, it can create large lighting area even flexible and/or transparent panels. The OLED has relatively similar spectrum to natural sun light 
compared to that of LED and OLED light sources that are already showing great aesthetic potential without glare.

Several companies already offer OLED products for general lighting applications. However current production lines are still small and prices are still high. But with mass production and higher efficacy, OLED will be one of the mainstream lighting sources in very near future. However, to replace conventional lighting with OLED products, long-term reliability characteristics of OLED panels and luminaires should be solved. There are some studies on long-term reliability characteristics of OLED light sources [6-15]. However, these studies focused on the light output degradation of OLED light sources mainly. In this paper, we have investigated long-term reliability characteristics of OLED panel and luminaries in terms of maintained optical and electrical characteristics such as lumen output, correlated color temperature (CCT), color rendering index (CRI), and operating voltage. To investigate the maintained characteristics dependences on the different panel shape, form factor, emitting surface size, and operating power, total twelve OLED panels with four different kinds and six OLED luminaires with two different kinds were analyzed up to six thousand hours for the general lighting applications. For example, to analyze the different panel shape effect on the long-term reliability with same emitting surface area, square shape panel (type A) and rectangle shape panel (type C) were tested. For the different form factor effect, flexible panel (type B) and rigid panel (type C) were compared. To check the emitting surface size dependence, small size panel (type C) and large size panel (type D) were analyzed. Finally, to investigate the operating power effect, high-power luminaire (type E) and low-power luminaire (type F) were studied.

This paper is organized as follows. In Section 2, experimental setup and selected various kind of samples under test are described. In Section 3, measured results about the long-term optical and electrical characteristics of OLED panels and luminaires with operating time of six thousand hours are shown and analyzed. Luminous output maintenance, correlated color temperature, and color rendering index maintenance and operating voltage maintenance characteristics of OLED panels and luminaires are analyzed in this section. Then, discussion on the results such as light spectrum variation and color shift is followed in Section 4. Finally the conclusion of this paper is presented in Section 5.

\section{Testing Samples and Experimental Setup}

\subsection{Testing Samples}

To investigate the long-term reliability characteristics of OLED light source, total twelve OLED panels with four different types were analyzed in this. For each kind of OLED panel, three samples were tested. The photos and physical, electrical, and optical characteristics of each sample used in experiments are shown in Table 1. OLED panel type A, C, and D have different size and type B and C have same size but type B is flexible type OLED panel where all other OLED panel types are rigid panel. To investigate the characteristic changes due to the different shape but having the same emitting surface area, type A (square shape) and type $C$ (rectangle shape) were selected and tested. To test long-term reliability differences due to the form factor type $\mathrm{B}$ (flexible) and type C (rigid) were selected and tested. Finally, to check the emitting surface area dependence, type $C$ (small) and type D (large) were selected and tested, respectively. All OLED panels used in these experiments were obtained commercially in the market and manufactured by LG Display. These OLED panels are based on active matrix OLED technology with 2 stacks emission material layer structures. All OLED panels used in this study were manufactured using same materials and production process. 
Table 1. Organic light-emitting diode (OLED) panels used in the experiment.

\begin{tabular}{|c|c|c|}
\hline Type & Photo of OLED Panel & Characteristics \\
\hline A & & $\begin{array}{ll}\text { - } & \text { Panel size: } 100 \mathrm{~mm} \times 100 \mathrm{~mm} \\
\text { - } & \text { Efficacy: } 50 \mathrm{~lm} / \mathrm{W} \\
\text { - } & \text { CCT: } 3700 \mathrm{~K}, \mathrm{CRI}: 90 \\
\text { - } & \text { Operating current: } 230 \mathrm{~mA} \text {, voltage: } 6 \mathrm{~V} \\
\text { - } & \text { Model number: LL055RS1-64P1-OY1 }\end{array}$ \\
\hline B & & $\begin{array}{ll}\text { - } & \text { Panel size: } 200 \mathrm{~mm} \times 50 \mathrm{~mm} \\
\text { - } & \text { Efficacy: } 50 \mathrm{~lm} / \mathrm{W} \\
\text { - } & \text { CCT: } 3700 \mathrm{~K}, \mathrm{CRI}: 90 \\
\text { - } & \text { Operating current: } 245 \mathrm{~mA} \text {, voltage } 6 \mathrm{~V} \\
\text { - } & \text { Flexible type panel } \\
\text { - } & \text { Model number: LL081FR1-64P1-OY1 }\end{array}$ \\
\hline $\mathrm{C}$ & & $\begin{array}{ll}\text { - } & \text { Panel size: } 200 \mathrm{~mm} \times 50 \mathrm{~mm} \\
\text { - } & \text { CCT: } 3700 \mathrm{~K}, \mathrm{CRI}: 90 \\
\text { - } & \text { Efficacy: } 50 \mathrm{~lm} / \mathrm{W} \\
\text { - } & \text { Operating current: } 230 \mathrm{~mA} \text {, voltage } 6 \mathrm{~V} \\
\text { - } & \text { Model number: LL081RR1-64P1-OY1 }\end{array}$ \\
\hline $\mathrm{D}$ & $\ldots \ldots+2 \div$ & $\begin{array}{ll}\text { - } & \text { Panel size: } 320 \mathrm{~mm} \times 110 \mathrm{~mm} \\
\text { - } & \text { Efficacy: } 40 \mathrm{~lm} / \mathrm{W} \\
\text { - } & \text { CCT: } 3700 \mathrm{~K}, \mathrm{CRI}: 90 \\
\text { - } & \text { Operating current: } 800 \mathrm{~mA} \text {, voltage 6 V } \\
\text { - } & \text { Model number: LL133RR1-64P1-OY1 }\end{array}$ \\
\hline
\end{tabular}

To investigate the long-term reliability characteristics of OLED luminaires, total six OLED luminaries with two different kinds were analyzed. For each kind of OLED luminaire, three samples were tested as similar to the OLED panels. The photos and physical, electrical, and optical characteristics of each sample used in experiments are shown in Table 2. In the experiments, to investigate the dependences on the long-term reliability characteristics due to the operating power, OLED luminaires have similar optical and color characteristics including CCT and CRI but with different rated power (type E: $11 \mathrm{~W}$, type F: $7 \mathrm{~W}$ ) were tested for the analysis. Type E luminaire was obtained commercially in the market and manufactured by LG Display and type F luminaire manufactured by OCLESS. OLED panels from LG Display were used in the luminaire.

Table 2. OLED luminaires used in the experiment.

\begin{tabular}{|c|c|c|}
\hline Type & Photo of OLED Luminaire & Characteristics \\
\hline $\mathrm{E}$ & & $\begin{array}{ll}\text { - } & \text { Luminaire size: } 322 \mathrm{~mm} \times 279 \mathrm{~mm} \times 384 \mathrm{~mm} \\
& (\mathrm{~W} / \mathrm{L} / \mathrm{H}) \\
\text { - } & \text { Total luminous flux: } 500 \mathrm{~lm} \\
\text { - } & \text { CCT: } 4000 \mathrm{~K}, \mathrm{CRI}: 88 \\
\text { - } & \text { Operating power: } 11 \mathrm{~W} \\
\text { - } & \text { Model number: SKY }\end{array}$ \\
\hline $\mathrm{F}$ & & $\begin{array}{ll}\text { - } & \text { Luminaire size: } 238 \mathrm{~mm} \times 45 \mathrm{~mm} \times 466 \mathrm{~mm} \\
& (\mathrm{~W} / \mathrm{L} / \mathrm{H}) \\
\text { - } & \text { Total luminous flux: } 200 \mathrm{~lm} \\
\text { - } & \text { CCT: } 4000 \mathrm{~K}, \mathrm{CRI}: 88 \\
\text { - } & \text { Operating power: } 7 \mathrm{~W} \\
\text { - } & \text { Model number: OCLESS-Gflex }\end{array}$ \\
\hline
\end{tabular}




\subsection{Experimental Setup}

Electrical and optical characteristics such as operating voltage, lumen output, luminous efficacy, CCT, CRI were measured up to six thousand hours with period of one thousand hour using integrating sphere measurement system with diameter of two meter as shown in Figure 1a. Recently, international commission on illumination (CIE) published the international standard for measurement method of OLED product used in general lighting [16]. All electrical and optical characteristics of OLED panels and luminaires are measured according to this international standard CIE S 025-SP1/E: 2019: Test Method for OLED Luminaires and OLED Light Sources. During the operation OLED samples were in the temperature controlled chamber with temperature of $25^{\circ} \mathrm{C}$ as shown in Figure 1b. In case of OLED luminaire, control gear to supply rated operating voltage was integrated in the luminaire. Thus additional power supply was not necessary to operate the OLED luminaire.

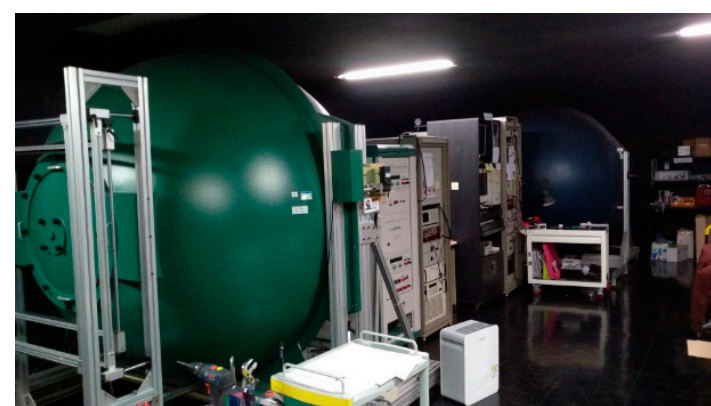

(a)

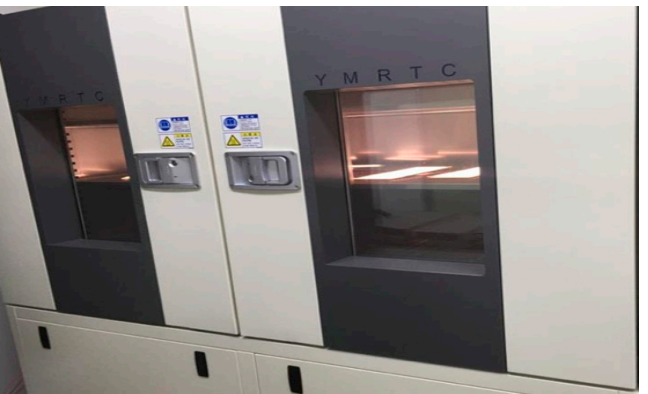

(b)

Figure 1. Experimental setup for operating OLED panels. (a) Integrating sphere measurement system for OLED products. (b) Operating conditions with fixed temperature in a chamber.

\section{Results and Analysis}

\subsection{Lumen Maintenance Characteristics of OLED Panels and Luminaires}

To investigate the long-term reliability of OLED light panels and luminaires, we have measured the maintained lumen output characteristics. Maintained lumen output of OLED panels and luminaires after six thousand hours to their initial value is shown in Figure $2 a, b$, respectively. All OLED panels show about $80 \%$ of lumen maintenance and similar degradation characteristics even at six thousand hours of operation. In case of OLED luminaires Type $\mathrm{E}$ and $\mathrm{F}$, lumen output degrades more steeply even at two thousand hours compared to OLED panels (type A, B, C, and D). This is because, in case of OLED luminaires, lumen degradation effect got worse by the effect of the control gear which is integrated in the luminaires and the overall luminaire design including thermal management. Moreover, the difference in the degradation pattern of OLED luminaires from one thousand hour to four thousand hour came from each unique design by the different luminaire manufactures.

To evaluate the lumen maintenance of OLED panel and luminaires, lumen output data of three samples in each type were averaged. As the results, the averaged lumen maintenance of each OLED type at six thousand hours aging was evaluated in Table 3. As shown in Table 3, lumen outputs of all OLED panels were maintained to $80 \%$ after six thousands operation with rated condition. However, in case of OLED luminaires, maintained lumen output was $50 \%$ for type $\mathrm{E}$ and $40 \%$ for type $\mathrm{F}$, respectively. For luminous efficacy, initial values of OLED panels were $50 \mathrm{~lm} / \mathrm{W}$ for OLED panel type A, B, and C and $40 \mathrm{~lm} / \mathrm{W}$ for OLED panel type D. After six thousand hours of operation, the luminous efficacy was decreased by amount of $10 \mathrm{~lm} / \mathrm{W}$. 


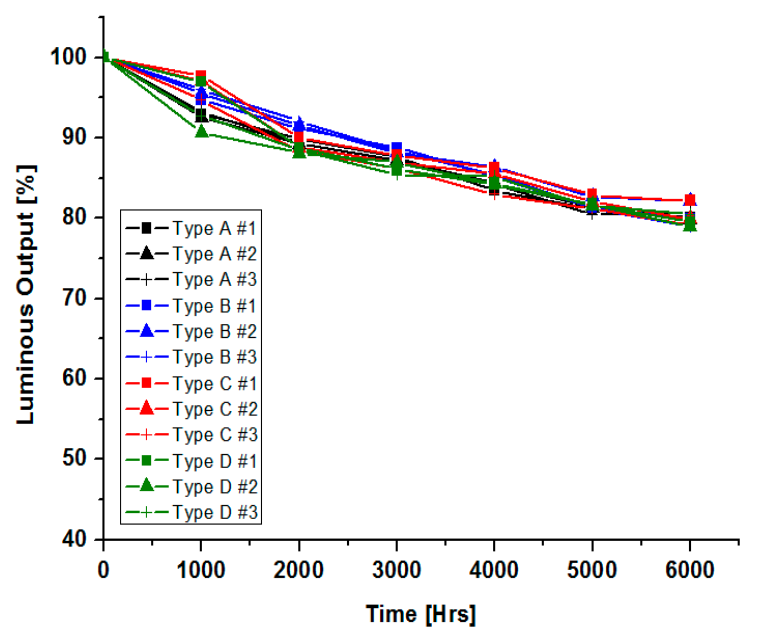

(a)

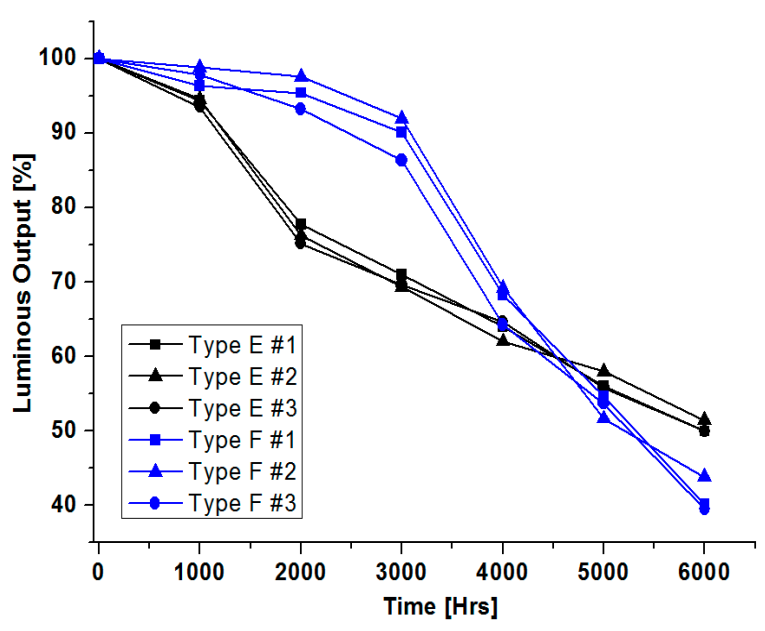

(b)

Figure 2. Characteristics of maintained lumen output of OLED products. (a) Maintained lumen output of OLED panels. (b) Maintained lumen output of OLED luminaires.

Table 3. Maintained lumen output and luminous efficacy of OLED panels and luminaires with operating of thousand hours.

\begin{tabular}{cccc}
\hline Type & $\begin{array}{c}\text { Maintained Lumen } \\
\text { Output at } \mathbf{6 0 0 0} \mathbf{h}[\mathbf{\%}]\end{array}$ & $\begin{array}{c}\text { Initial Luminous } \\
\text { Efficacy }[\mathbf{l m} / \mathrm{W}]\end{array}$ & $\begin{array}{c}\text { Maintained Luminous } \\
\text { Efficacy at } \mathbf{6 0 0 0} \mathbf{h}[\mathbf{l m} / \mathbf{W}]\end{array}$ \\
\hline A & $79.60 \%$ & $48.08[\mathrm{~lm} / \mathrm{W}]$ & $38.44[\mathrm{~lm} / \mathrm{W}]$ \\
B & $79.52 \%$ & $47.16[1 \mathrm{~m} / \mathrm{W}]$ & $37.88[\mathrm{~lm} / \mathrm{W}]$ \\
C & $78.57 \%$ & $49.53[\mathrm{~lm} / \mathrm{W}]$ & $39.83[\mathrm{~lm} / \mathrm{W}]$ \\
$\mathrm{D}$ & $78.16 \%$ & $39.64[\mathrm{~lm} / \mathrm{W}]$ & $31.58[\mathrm{~lm} / \mathrm{W}]$ \\
E & $50.47 \%$ & $21.28[1 \mathrm{~m} / \mathrm{W}]$ & $9.41[\mathrm{~lm} / \mathrm{W}]$ \\
F & $41.19 \%$ & $22.64[1 \mathrm{~m} / \mathrm{W}]$ & $8.14[\mathrm{~lm} / \mathrm{W}]$ \\
\hline
\end{tabular}

International Electrotechnical Commission (IEC) technical committee 34 (title: lighting) has responsibility for safety and performance standard of OLED product for general lighting. Up to date, there is no international standard or industry standard, i.e., de facto standard for lifetime estimation of OLED product for general lighting. However, IEC 62922 (OLED panels for general lighting-Performance requirements) [17] standard, now in amendment stage, covers lifetime issue of OLED product for general lighting. In this amendment, process for lifetime evaluation is similar to that of LED packages for general lighting applications. To evaluate the lifetime of LED packages, there were many discussions over the couple of years. Then ANSI/IES TM-21: Projecting Long Term Lumen, Photon, and Radiant Flux Maintenance of LED Light Sources standard [18] and IEC 63013: 2017: LED packages—Long-term luminous and radiant flux maintenance projection standard [19] were developed and well adopted in the lighting industry.

In these standard, exponential least squares curve-fit method was used with averaged normalized luminous flux data as shown in Equation (1).

$$
\Phi(t)=B \exp (-\alpha t)
$$

where:

$t=$ operating time in hours

$\Phi(t)=$ averaged normalized luminous flux output at time $t$

$B=$ projected initial constant derived by the least squares curve-fit

$\alpha=$ decay rate constant derived by the least squares curve-fit 
The following Equation (2) was used to project lumen maintenance lifetime.

$$
L p(D \mathrm{k})=\frac{\ln \left(100 \times \frac{B}{p}\right)}{\alpha}
$$

where:

$L p=$ lumen maintenance life expressed in hours where $p$ is the percentage of initial luminous flux that is maintained

$D=$ total duration time divided by 1000 and rounded to the nearest integer

Above Equations (1) and (2) were used to evaluate the lifetime of OLED panels and luminaires with six thousand hours data, the results are shown in Table 4. Reported L70(6k) means that a lifetime of OLED product which maintains $70 \%$ of its initial luminous flux output, and the reported L70(6k) using extrapolation method in IES TM-21 standard was over ten thousand hours for all type of OLED panels (type A, B, C, and D) and under five thousand hours for OLED luminaires (type $\mathrm{E}$ and F). In case of reported L50(6k) means that a lifetime of OLED product which maintains $50 \%$ of its initial luminous flux output, and the reported L50(6k) was over twenty thousand hours for all type of OLED panels (type A, B, C, and D) and under six thousand hours for OLED luminaires (type E and F). Alpha parameter and B parameter for all four types of OLED panels have similar values, thus all OLED panels have same degradation mechanism. Actually, these four types of OLED panels were manufactured by same manufacturer and fabrication process, thus their alpha parameter and B parameter are very similar to each other. In case of OLED luminaires, we had same results as shown in Table 4. Remarkably, flexible OLED panel (type B) show equivalent reliability characteristics to that of rigid OLED panel (type C) which has the same dimensions and operating conditions. Maximum error between the measured lumen degradation data and the predictive model at six thousand hours was about $2 \%$ for all cases.

Table 4. Evaluated lifetime of OLED panels and luminaires with operating of six thousand hours.

\begin{tabular}{ccccc}
\hline Type & $\begin{array}{c}\text { Reported L70(6k) } \\
\text { [hours] }\end{array}$ & $\begin{array}{c}\text { Reported L50(6k) } \\
\text { [hours] }\end{array}$ & $\boldsymbol{\alpha}$ & B \\
\hline A & 11,000 & 22,000 & $2.853 \times 10^{-5}$ & 0.945 \\
B & 10,000 & 20,000 & $3.332 \times 10^{-5}$ & 0.976 \\
C & 10,000 & 20,000 & $3.372 \times 10^{-5}$ & 0.973 \\
D & 10,000 & 21,000 & $3.044 \times 10^{-5}$ & 0.942 \\
E & 3000 & 6000 & $1.175 \times 10^{-4}$ & 1.013 \\
F & 4000 & 5000 & $1.814 \times 10^{-4}$ & 1.331 \\
\hline
\end{tabular}

\subsection{Color Maintenance Characteristics of OLED Panels and Luminaires}

Because humans may perceive the shift of CCT over $100 \mathrm{~K}$ at warm color temperature range, the amount of shift in OLED products with operating is one of the critical points of OLED products for general lighting applications. To evaluate maintained CCT characteristics of OLED panel and luminaries, CCT shift data of three samples in each type were averaged as shown in Figure 3.

The amount of CCT shift was below $100 \mathrm{~K}$ with OLED panel type A, B, and C. Only type D OLED panel shows CCT shift over $100 \mathrm{~K}$ after six thousand hours as shown in Figure 3 and Table 5. Even in this case the difference of each three samples is very small. Thus CCT maintenance characteristics of OLED panels are not inferior to that of LED light sources [20]. The reason on relative large shift of type D OLED panel is that the type $\mathrm{D}$ is the largest OLED panel and operated with high operating current of $800 \mathrm{~mA}$. The surface area of type D OLED panel is bigger than that of other OLED panel type by three times. Thus the total CCT shift was accumulated along the surface area. In case of OLED luminaires, the amount of CCT shift reached to over $100 \mathrm{~K}$ during the experiment. 


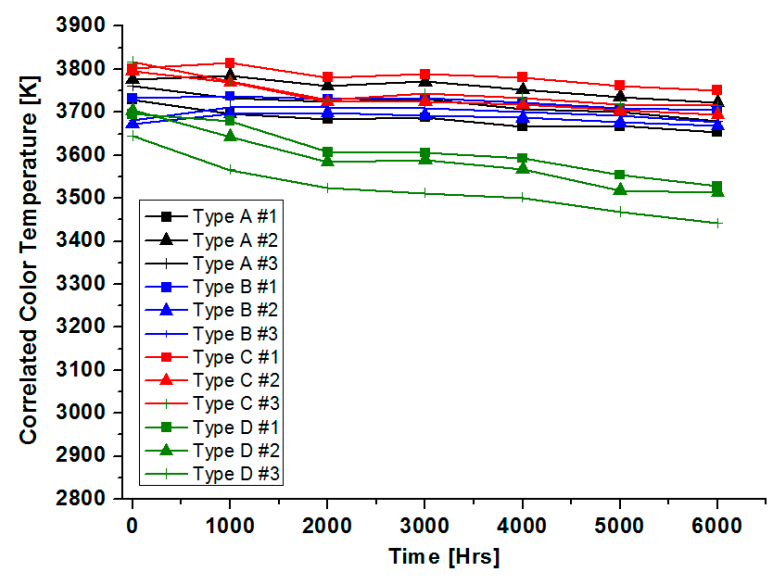

(a)

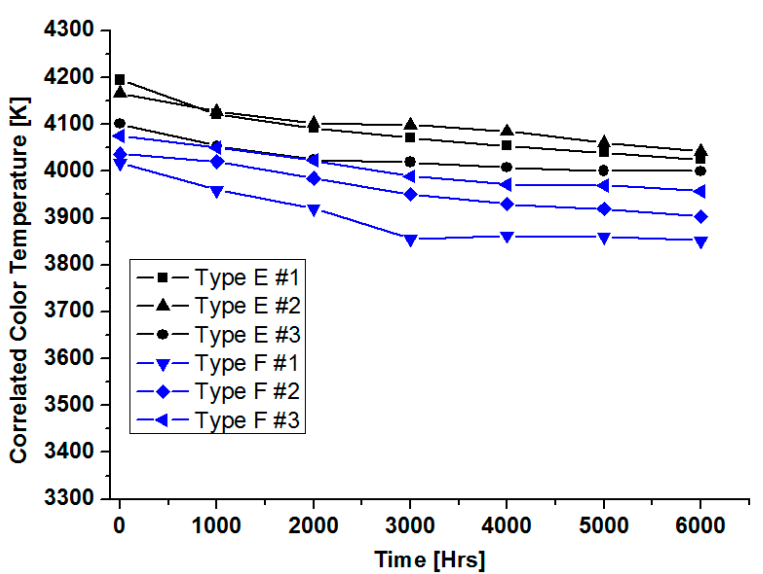

(b)

Figure 3. Characteristics of maintained correlated color temperature (CCT) of OLED products. (a) Maintained CCT of OLED panels. (b) Maintained CCT of OLED luminaires.

Table 5. CCT maintenance characteristics of OLED products with operating of six thousand hours.

\begin{tabular}{cccc}
\hline Type & Initial CCT [K] & Maintained CCT [K] & Delta CCT [K] \\
\hline A & 3755 & 3685 & 70 \\
B & 3695 & 3684 & 11 \\
C & 3804 & 3720 & 84 \\
D & 3682 & 3494 & 187 \\
E & 4154 & 4022 & 132 \\
F & 4043 & 3904 & 139 \\
\hline
\end{tabular}

CRI is one of the parameters that provide quality of light for general lighting applications. Maintained CRI characteristics of OLED panels and luminaries after six thousand hours are shown in Table 6. The initial CRI of all OLED panels are about 90 and the decrease of CRI after six thousand hours within 2 for OLED panels and 3 for OLED luminaires in the experiments.

Table 6. Color rendering index (CRI) maintenance characteristics of OLED products with operating of six thousand hours.

\begin{tabular}{cccc}
\hline Type & Initial CRI & Maintained CRI & Delta CRI \\
\hline A & 90 & 89 & 1 \\
B & 89 & 88 & 1 \\
C & 90 & 89 & 1 \\
D & 91 & 89 & 2 \\
E & 90 & 87 & 3 \\
F & 90 & 87 & 3 \\
\hline
\end{tabular}

\subsection{Electrical Maintenance Characteristics of OLED Panels and Luminaires}

To evaluate the electrical maintenance characteristics of OLED products, operating voltage and power were measured up to six thousand hours while applying constant current to them. Maintained operating voltage required to supply constant current for OLED products tended to rise during long operation because of degradation of OLED products as shown in Table 7. In case of OLED panels, the increment of operating voltage after six thousand hours was $0.07 \mathrm{~V}$ (type A), $0.34 \mathrm{~V}$ (type B), $0.29 \mathrm{~V}$ (type C), and $0.22 \mathrm{~V}$ (type D), respectively. It means that maximum increment of operating voltage for OLED panels is less than $6 \%$. However, for the OLED luminaires, the increment of operating voltage after six thousand hours came to $0.71 \mathrm{~V}$ (type E) and $1.01 \mathrm{~V}$ (type F). Thus, the maximum 
increment of operating voltage for OLED luminaires is about 16\%. In the IEC 62922 which is performance requirements standard, the manufacturer declares the maintained operating voltage value at two thousand hours, then the operating voltage should not exceed the declared value with operation of two thousand hours. Thus necessity of the dedicated OLED control gear turns out in this study because LED control gear was used generally for OLED panel in the market.

Table 7. Operating voltage maintenance characteristics of OLED products after aging of $6000 \mathrm{~h}$.

\begin{tabular}{cccc}
\hline Type & $\begin{array}{c}\text { Initial Operating } \\
\text { Voltage [V] }\end{array}$ & $\begin{array}{c}\text { Maintained Operating } \\
\text { Voltage [V] }\end{array}$ & $\begin{array}{c}\text { Delta Operating } \\
\text { Voltage [V] }\end{array}$ \\
\hline $\mathrm{A}$ & 6.03 & 6.11 & $0.07(1.2 \%)$ \\
$\mathrm{B}$ & 6.20 & 6.54 & $0.34(5.5 \%)$ \\
$\mathrm{C}$ & 6.09 & 6.38 & $0.29(4.8 \%)$ \\
$\mathrm{D}$ & 6.06 & 6.28 & $0.22(3.6 \%)$ \\
$\mathrm{E}$ & 6.71 & 7.42 & $0.71(10.6 \%)$ \\
$\mathrm{F}$ & 6.41 & 7.42 & $1.01(15.8 \%)$ \\
\hline
\end{tabular}

\section{Discussion}

As discussed in the Section 3.2, color quality of OLED products is the critical factor for the general lighting applications. To investigate the mechanism of CCT shift, spectrum change with operating time for OLED panel and luminaire were analyzed as shown in Figure 4. Figure 4a shows the normalized spectrum of type A OLED panel and Figure $4 \mathrm{~b}$ shows that of type E OLED luminaires. In case of OLED panel, as the operating time increases then the normalized blue spectrum goes down while other spectrum maintain its initial ratio. However, in case of OLED luminaires the degradation of blue spectrum dramatically changes even at two thousands of operating hours. Green spectrum undergoes additional variation which is not measured in the OLED panel.

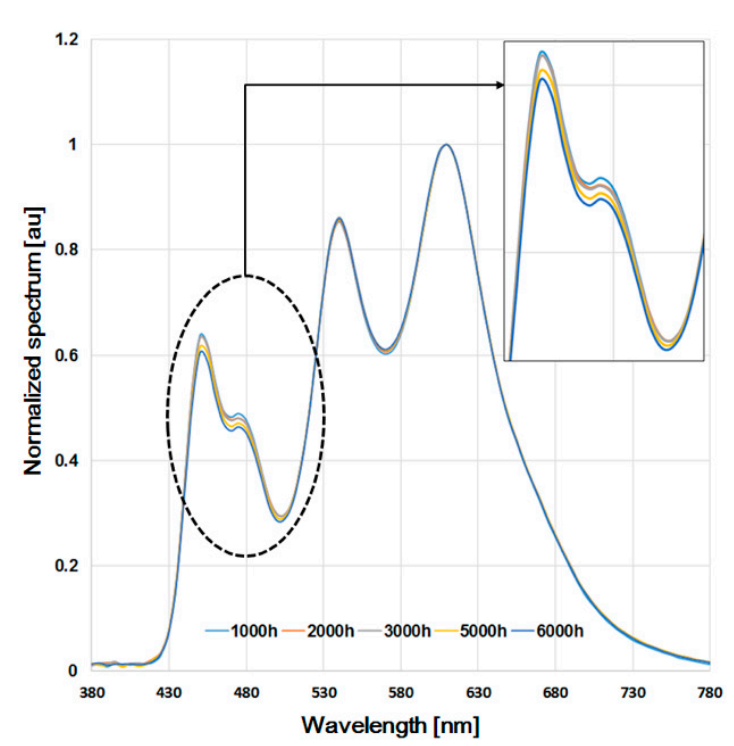

(a)

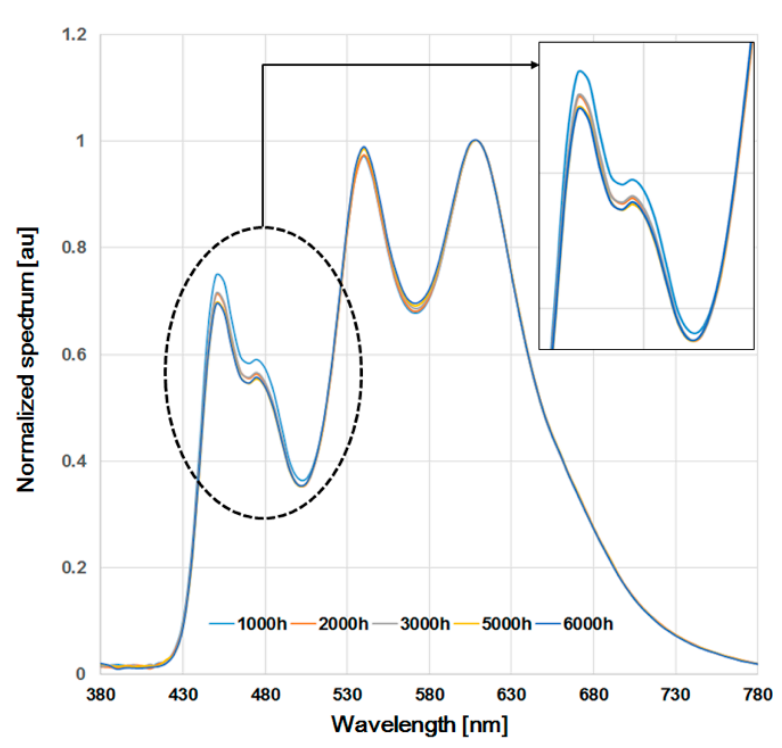

(b)

Figure 4. Normalized spectrum variation with operating time. (a) OLED panel type A (b) OLED luminaire type E.

To analyze the effect of panel size on the color quality, variation in CIE 1976 color coordinates of OLED panel type C (200 $\mathrm{mm} \times 50 \mathrm{~mm})$ and OLED panel type D (320 mm $\times 110 \mathrm{~mm}$ ) were evaluated. Measured $\mathrm{u}^{\prime}$ and $\mathrm{v}^{\prime}$ variation of OLED panel type $C$ and $D$ have similar tendency with operating time up to six thousand hours shown in Figure 5a. Amount and direction of $\mathrm{u}^{\prime}$ and $\mathrm{v}^{\prime}$ shifts in each type of OLED panel are almost same even 
with different initial $\mathrm{u}^{\prime}$ and $\mathrm{v}^{\prime}$ points. Such characteristics are more clearly identified by $\Delta \mathrm{u}^{\prime}$ and $\Delta v^{\prime}$ values as shown in Figure $5 \mathrm{~b}$. Because of the decrease in the blue spectrum, main direction of this shift heads for yellow-red direction [20,21]. Amount of maximum shift in OLED panel type D compared to that of OLED panel type C is over 2.4 times in $\Delta u^{\prime}$ and 2.0 times in $\Delta \mathbf{v}^{\prime}$, respectively. Thus, in case of OLED panel which has large surface area needs more careful design in the applications to maintain color quality.

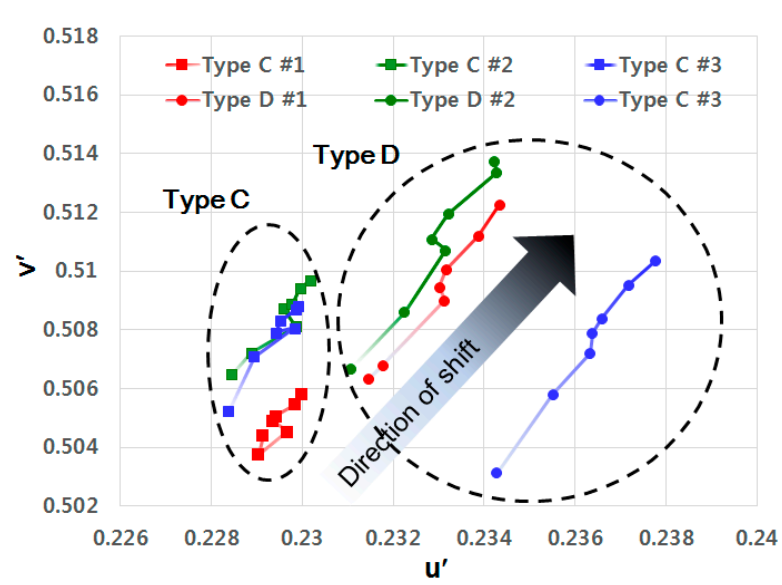

(a)

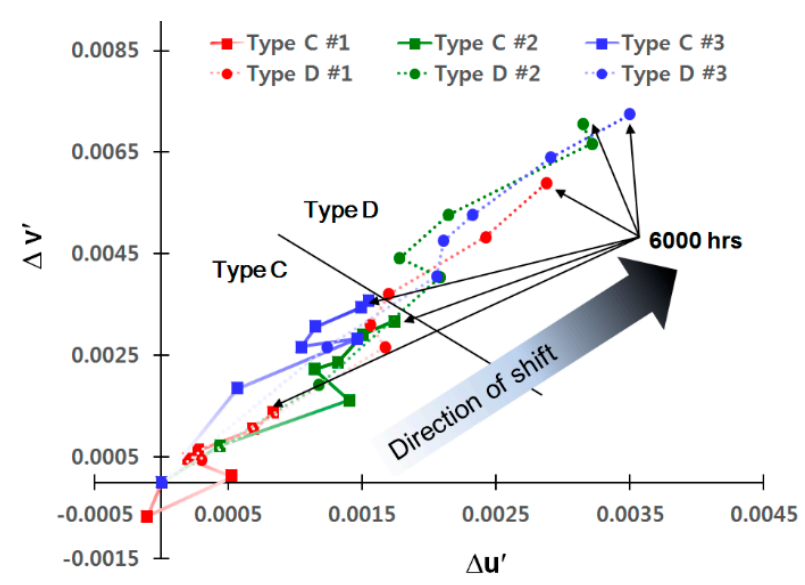

(b)

Figure 5. Color shift of OLED panel dependence on panel size. (a) OLED panel type C. (b) OLED panel type D.

In case of OLED luminaire, color shift has two different kind of mechanism as shown in Figure 6a,b. One is yellow-red shift as similar in OLED panel case up to two thousand hours of operation and the other is green shift due to the variation in green spectrum as shown in Figure $4 \mathrm{a}, \mathrm{b}$ from two thousand hours to six thousand hours of operation. Amount of maximum shift in OLED luminaire comes to 0.0013 in $\Delta \mathrm{u}^{\prime}$ and 0.0071 in $\Delta \mathrm{v}^{\prime}$, respectively.

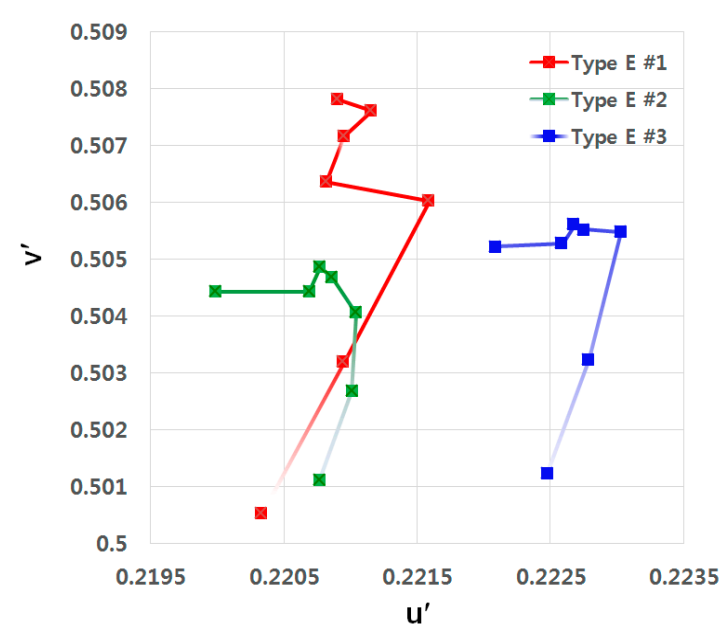

(a)

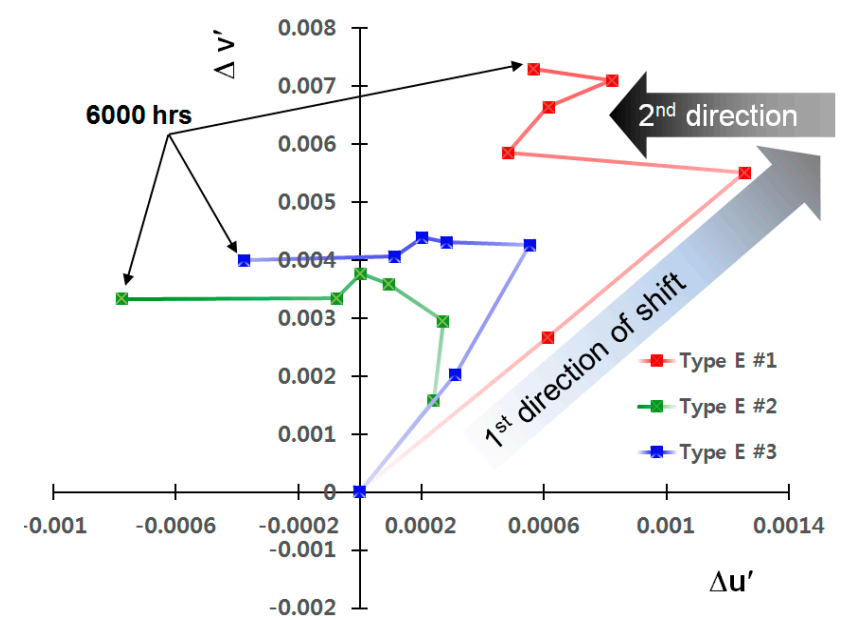

(b)

Figure 6. Color shift of OLED luminaire type E. (a) $\mathrm{u}^{\prime}$ and $\mathrm{v}^{\prime}$ color shift of luminaire type E. (b) $\Delta \mathrm{u}^{\prime}$ and $\Delta \mathrm{v}^{\prime}$ variations of luminaire type E. 


\section{Conclusions}

In this paper, we have investigated the various long-term reliability characteristics of OLED products in terms of lumen output, luminous efficacy, CCT, CRI, and operating voltage for the general lighting applications. Total twelve OLED panels with four different types and six OLED luminaires with two different types were analyzed up to six thousand hours. Long-term reliability dependences due to the different OLED panel shape, form factor, and emitting surface area were measured and analyzed.

Evaluated lifetime of OLED panels is about ten thousand hours for L70 lifetime and two thousand hours for L50 lifetime with extrapolation method based on IES TM-21 and IEC 63013 standard (including flexible type OLED panel and OLED panel which has large surface area). The shift of CCT in most OLED panels is below $100 \mathrm{~K}$. The decrease of CRI and increase of operating voltage are acceptable for general lighting applications as required in IEC 62922 standard. Thus long-term reliability of OLED panels is good enough for the general lighting applications.

However, in case of OLEDs panel which has large surface area shows inferior color maintenance characteristics compared to small size OLED panel. Moreover, OLED luminaries show the room for improvement in lifetime and color maintenance performances for the general lighting applications. More careful design and use of dedicated control gear for OLED luminaires will accelerate the adoption of OLED product in the market.

Author Contributions: Conceptualization, J.K.; formal analysis, J.K. and Y.C.; investigation, J.K. and Y.C.; resources, Y.C.; writing—original draft preparation, J.K.; writing—review and editing, W.J.; supervision, W.J. All authors have read and agreed to the published version of the manuscript.

Funding: This work is supported by the Korea Agency for Infrastructure Technology Advancement (KAIA) grant funded by the Ministry of Land, Infrastructure and Transport (Grant 19PQWO-B153369-01).

Institutional Review Board Statement: Not applicable.

Informed Consent Statement: Not applicable.

Data Availability Statement: The data presented in this study are available on request from the corresponding author.

Conflicts of Interest: The authors declare no conflict of interest.

\section{References}

1. Trevisanello, L.; Meneghini, M.; Mura, G.; Vanzi, M.; Pavesi, M.; Meneghesso, G.; Zanoni, E. Accelerated Life Test of High Brightness Light Emitting Diodes. IEEE Trans. Device Mater. Reliab. 2008, 8, 304-311. [CrossRef]

2. Kang, J.M.; Choi, J.H.; Kim, D.H.; Kim, J.W.; Song, Y.S.; Kim, G.H.; Han, S.K. Fabrication and Thermal Analysis of Wafer-Level Light-Emitting Diode Packages. IEEE Electron. Dev. Lett. 2008, 29, 1118-1120. [CrossRef]

3. Zhao, L.X.; Thrush, E.J.; Humphreys, C.J.; Phillipsa, W.A. Degradation of GaN-based quantum well light-emitting diodes. J. Appl. Phys. 2008, 103, 024501. [CrossRef]

4. Kang, J.M.; Kim, J.W.; Choi, J.H.; Kim, D.H.; Kwon, H.K. Life-time estimation of high-power blue light-emitting diode chips. Microelectron. Reliab. 2009, 49, 1231-1235. [CrossRef]

5. Scientific Committee on Health, Environmental and Emerging Risks (SCHEER). Final Opinion on Potential Risks to Human Health of Light Emitting Diodes; European Commission: Brussels, Belgium, 2018.

6. Xia, S.C.; Kwong, R.C.; Adamovich, V.I.; Weaver, M.S.; Brown, J.J. OLED device operational lifetime: Insights and challenges. In Proceedings of the 45th Annual IEEE International Reliability Physics Symposium, Phoenix, AZ, USA, 15-19 April 2007; pp. 253-257.

7. Zhou, X.; He, J.; Liao, L.S.; Lu, M.; Ding, M.X.; Hou, Y.X.; Zhang, M.X.; He, Q.X.; Lee, T.S. Real-time observation of temperature rise and thermal breakdown processes in organic LEDs using an IR imaging and analysis system. Adv. Mater. 2000, 12, 265-269. [CrossRef]

8. Alchaddoud, A.; Canale, L.; Ibrahem, G.; Zissis, G. Photometric and Electrical Characterizations of Large-Area OLEDs Aged Under Thermal and Electrical Stresses. IEEE Trans. Ind. Appl. 2018, 55, 991-995. [CrossRef]

9. Park, J.I.; Bae, S.J. Direct prediction methods on lifetime distribution of organic light-emitting diodes from accelerated degradation tests. IEEE Trans. Reliab. 2010, 59, 74-90. [CrossRef]

10. Cester, A.; Bari, D.; Framarin, J.; Meneghesso, N.W.G.; Xia, S.; Adamovich, V.; Brown, J.J. Thermal and electrical stress effects of electrical and optical characteristics of Alq3/NPD OLED. Microelectron. Reliab. 2010, 50, 1866-1870. [CrossRef] 
11. Kwak, K.; Cho, K.; Kim, S. Analysis of thermal degradation of organic light-emitting diodes with infrared imaging and impedance spectroscopy. Opt. Express 2013, 21, 29558-29566. [CrossRef] [PubMed]

12. Salameh, F.; Haddad, A.; Picot, A.; Canale, L.; Zissis, G.; Chabert, M.; Maussion, P. Modeling the Luminance Degradation of OLEDs Using Design of Experiments. IEEE Trans. Ind. Appl. 2019, 55, 6548-6558. [CrossRef]

13. Zhang, J.; Zhou, T.; Wu, H.; Liu, Y.; Wu, W.; Ren, J. Constant-step-stress accelerated life test of white OLED under Weibull distribution case. IEEE Trans. Electron Devices 2012, 59, 715-720. [CrossRef]

14. Zhang, J.; Liu, F.; Liu, Y.; Wu, H.; Wu, W.; Zhou, A. A study of accelerated life test of white OLED based on maximum likelihood estimation using lognormal distribution. IEEE Trans. Electron. Devices 2012, 59, 3401-3404. [CrossRef]

15. Kim, H.; Shin, H.; Park, J.; Choi, Y.; Park, J. Statistical modeling and reliability prediction for transient luminance degradation of flexible OLEDs. In Proceedings of the 2018 IEEE International Reliability Physics Symposium (IRPS), Burlingame, CA, USA, 11-15 March 2018.

16. CIE. DIS 025-SP1/E:2019, Test Method for OLED Luminaires and OLED Light Sources. Available online: http://cie.co.at/ publications / test-method-oled-luminaires-and-oled-light-sources-0 (accessed on 8 October 2020).

17. IEC 62922/AMD1 ED1. Organic Light Emitting Diode Panels for General Lighting_Performance Requirements. Available online: https: / / www.iec.ch/dyn/www / f?p=103:38:14509173073973::::FSP_ORG_ID,FSP_APEX_PAGE,FSP_PROJECT_ID:13 40,23,101920 (accessed on 8 October 2020).

18. IES TM-21-11. Projecting Long Term Lumen Maintenance of LED Light Sources. Available online: https:/ / webstore.ansi.org/ standards/iesna/iestm2111 (accessed on 8 October 2020).

19. IEC 63013 ED1. LED Packages_Long-Term Luminous and Radiant Flux Maintenance Projection. Available online: https: / / webstore.iec.ch/publication/28210 (accessed on 8 October 2020).

20. LED Systems Reliability Consortium. LED Luminaire Reliability: Impact of Color Shift; Next Generation Lighting Industry Alliance: Duluth, GA, USA, 2017.

21. Mehr, M.Y.; Bahrami, A.; van Driel, W.D.; Fan, X.J.; Davis, J.L.; Zhang, G.Q. Degradation of optical materials in solid-state lighting systems. Int. Mater. Rev. 2020, 65, 102-128. [CrossRef] 